\title{
The Prospect for Potent Sodium Voltage-Gated Channel Blockers to Relieve an Excessive Cough
}

\author{
Mariana BROZMANOVA ${ }^{1}$, Nikoleta PAVELKOVA ${ }^{1}$ \\ ${ }^{1}$ Department of Pathophysiology, Jessenius Faculty of Medicine, Comenius University, Martin, \\ Slovakia
}

Received September 15, 2019

Accepted November 8, 2019

\section{Summary}

An excessive, irritable, productive or non-productive coughing associated with airway inflammation belongs to pathological cough. Increased activation of airway vagal nociceptors in pathological conditions results from dysregulation of the neural pathway that controls cough. A variety of mediators associated with airway inflammation overstimulate these vagal airway fibers including C-fibers leading to hypersensitivity and hyperreactivity. Because current antitussives have limited efficacy and unwanted side effects there is a continual demand for the development of a novel more effective antitussives for a new efficacious and safe cough treatment. Therefore, inhibiting the activity of these vagal C-fibers represents a rational approach to the development of effective antitussive drugs. This may be achieved by blocking inflammatory mediator receptors or by blocking the generator potential associated with the specific ion channels. Because voltage-gated sodium channels ( $\mathrm{NaVs}$ ) are absolutely required for action potentials initiation and conduction irrespective of the stimulus, NaVs become a promising neural target. There is evidence that NaV1.7, 1.8 and 1.9 subtypes are predominantly expressed in airway cough-triggering nerves. The advantage of blocking these NaVs is suppressing C-fiber irrespective to stimuli, but the disadvantage is that by suppressing the nerves is may also block beneficial sensations and neuronal reflex behavior. The concept is that new antitussive drugs would have the benefit of targeting peripheral airway nociceptors without inhibiting the protective cough reflex.

\section{Key words}

Airway sensory nerves $\bullet$ A-fibers $\bullet$ C-fibers $\bullet$ Cough $\bullet$ Voltagegated sodium channel blockers

\section{Corresponding author}

Mariana Brozmanova, Dept. of Pathophysiology, Jessenius Faculty of Medicine, Comenius University, Mala Hora C, 03601 Martin, Slovakia. E-mail: brozmanova@jfmed.uniba.sk

\section{Introduction}

Cough is a very frequent symptom and a reason to visit the doctor. On one side cough is an effective defensive reflex that protects the airways and lungs from aspirate, inhaled particulate matter, accumulated secretion or other irritants. On the other side, when cough ceases to fulfil its physiological role and when becomes a pathological one and occurs as a common symptom in a variety of acute and chronic respiratory diseases. This cough becomes too excessive, irritative, strongly productive or non-productive according to the origin. It is often painful and finally adversely impacts patients' quality of life (Kollarik et al. 2010, Canning et al. 2014).

Acute cough that lasts less than 8 weeks and is usually a result of an acute viral or bacterial upper respiratory tract infection. Chronic cough lasts for over 8 weeks and commonly occurs in chronic respiratory diseases such as bronchial asthma, chronic obstructive pulmonary disease (COPD), idiopathic pulmonary fibrosis (IPF), and lung cancer, or can be idiopathic in origin (Canning et al. 2014, Bonvini and Belvisi 2017). Pathological cough in disease is persistent and hypersensitive, occurring in response to stimuli which do not normally evoke cough. This enhanced sensitivity to tussive or non-tussive stimuli is referred to as chronic cough hypersensitivity syndrome which is a common 
symptom in chronic respiratory diseases (Mazzone and Undem 2016, Song and Morice 2017, Brozmanova et al. 2008).

Despite the fact that a lot of money is spent every year on the cough medication, it seems from clinical practice that the currently used antitussive therapies are largely ineffective. One of the most effective antitussive drug groups is opiates (codeine), which act both centrally on brainstem via opioid receptors and on receptors located peripherally on sensory nerve terminals in the airways. However, at their effective doses, they have dangerous adverse effects such as dependence, respiratory depression, sedation or gastrointestinal complications (Belvisi and Geppetti 2004, Barnes 2007). Surprisingly, one clinical trial has shown that codeine - the current gold standard in cough treatment, was no more effective than placebo in patients with COPD (Smith et al. 2006). Because of the high incidence of chronic cough with adverse consequences, there is a continuous demand for the development of a novel, more effective antitussive for a new efficacious and safe cough treatment. Therefore, the identification of new neural target would be a huge benefit for people suffering from chronic respiratory diseases. The ideal therapeutic strategy would represent inhibition of pathological cough by selectively inhibiting mainly jugular C-fibers with preservation of the protective cough reflex (mainly evoked by nodose $\mathrm{A} \delta$-fibers) for maintaining airway patency and preventing lung infections.

\section{Airway sensory nerves and cough}

Extensive experimental studies in animals and an increasing number of studies conducted in human subjects have increased our understanding about neural pathway regulating the cough reflex (Canning et al. 2014, Mazzone 2005, Mazzone and Undem, 2016, Song and Morice 2017, Pecova et al. 2008, Brozmanova et al. 2006, Brozmanova et al. 2008, Brozmanova et al. 2012, Plevkova et al. 2004, Plevkova et al. 2013).

Cough is initiated when at least two subtypes of airway vagal sensory nerves are stimulated with distinction in their chemical and mechanical responsiveness according to their anatomic, embryological and physiological characteristics. Studies in guinea pigs indicate that cough reflex is independently regulated by these nerve subtypes. They involve nociceptive C-fibers derived from the jugular ganglia mediating mainly chemically-induced cough. They are unmyelinated and slowly conducting C-fibers with terminals found in and around the mucosal surface of the larynx, trachea, bronchi, and alveoli. C-fibers as nociceptors detect a range of noxious chemical irritants but are relatively insensitive to mechanical stimuli. They are sensitive to a variety of inhaled or locally produced chemical mediators, which may either activate or sensitize nociceptor nerve endings. These nociceptors are also responsive to pro-inflammatory molecules, including bradykinin, prostaglandins, leukotrienes and cytokines. C-fibers are also selectively activated by capsaicin, protons, nicotine or activators of TRPA1. Each of these stimuli initiate coughing in patients and awake animals (Andre et al. 2009, Canning et al. 2006, Canning et al. 2014, Mazzone and Undem 2016, West et al. 2015, Taylor-Clark et al. 2008, Taylor-Clark et al. 2009, Bonvini and Belvisi 2017, Brozmanova et al. 2012, Plevkova et al. 2004, Pecova et al. 2008, Ji et al. 2018).

Mechanosensitive "cough receptors" derived from the nodose ganglia mediate mainly mechanicallyinduced cough, occurring during protection and cleaning of airways. They are myelinated and fast conducting $\mathrm{A} \delta$ fibers with terminals found underneath the epithelium in the large airways. They are mainly sensitive to touch-like mechanical stimuli, intraluminal irritants delivered to the mucosal surface such particulate matter but they are relatively insensitive to most chemical mediators with exception of low pH (Canning et al. 2006, Canning et al. 2014, Mazzone and Undem, 2016, West et al. 2015).

Activation of the aforementioned airway sensory nerves causes membrane depolarization of the terminal membrane. If the depolarization is of sufficient magnitude and it reaches a certain threshold (around -55 millivolts), then it leads to the formation of the all-ornothing action potential via activation of voltage-gated sodium channels (NaVs). Action potentials are conducted along the axon to the central terminations in the brainstem. The nodose neurons have their central terminations well-defined in the nucleus of the solitary tract (nTS), whereas jugular neurons have been recently shown to terminate in the paratrigeminal nucleus (Pa5). These sensory nuclei relay signal to the respiratory central pattern generator within the brainstem, which is responsible for reflex coughing, as well as to higher brain structures for the perception of airway irritation, which are needed for behavioral modulation of coughing (Canning et al. 2006, Canning et al. 2014, Taylor-Clark 2015, Mazzone and Undem 2016). 


\section{Ion channels in activation of airway sensory nerves and cough}

Several transient receptor potential (TRP) channels are expressed on airway sensory nerve terminals, namely the temperature-sensitive transient receptor potential vanilloid-1 (TRPV1), transient receptor potential vanilloid-4 (TRPV4), transient receptor potential ankyrin-1 (TRPA1) and transient receptor potential melastatin-8 (TRPM8), which are implicated in the afferent arm of the cough reflex (Grace et al. 2014). These TRP channels as ligand-gated ion channels have been described in dorsal root ganglia. They are emerging as sensory transducers that may participate in the generation of pain sensation evoked by chemical, thermal and mechanical stimuli (Levine and Alessandri-Haber 2007). Recent studies in mice deficient in TRP channels indicate that TRP channels may play a crucial role in the hypersensitivity to thermal, chemical and mechanical stimuli that are associated with peripheral inflammation and neuropathic pain (Levine and Alessandri-Haber 2007).

$T R P V 1$, originally named vanilloid receptor 1 (VR 1) is commonly referred to as the capsaicin receptor. TRPV1 is a $\mathrm{Ca}^{2+}$ permeable non-selective ion channel. TRPV1 was first described as a polymodal receptor activated by three pain-producing stimuli: vanilloid compounds (capsaicin, resiniferatoxin), moderate heat $\left(\geq 43^{\circ} \mathrm{C}\right)$ and a low $\mathrm{pH}(<5.9)$ and is highly expressed in dorsal root ganglia, trigeminal and vagal ganglia (Caterina et al. 1997). TRPV1 can be also indirectly activated through protein-coupled receptors (GPCRs) when diverse agonists bind to GPCRs and initiate signalling pathway with subsequent activation of TRPV1. These agonists include bradykinin, prostaglandin $\mathrm{E}_{2}$, extracellular ATP and Protein Activated Receptor 2 (PAR2) (Grace et al. 2012, Kollarik and Undem 2004, Chen et al. 2017). Noxious exogenous irritants such as capsaicin and resiniferatoxin and some endogenous mediators such as acid bind directly to and open TRPV1 ion channels (Caterina et al. 1997). Some agonists are thought to be able to both activate and sensitize TRPV1 channels, and it is not always possible to distinguish whether acts as a direct opener or rather as a sensitizer, which lowers the activation threshold for another stimulus. TRPV1 activation by capsaicin as a common tussive agent to evoke cough has been well documented in human and animals (Lallo et al. 1995, Mazzone 2005, Brozmanova et al. 2012).
TRPA1 (ankyrin 1) is a nonselective cationic TRP channel expressed in nociceptors, including spinal dorsal root ganglia (DRG), nasal trigeminal neurons and it is widely expressed in vagal airway neurons (Nassenstein et al. 2008, Bautista et al. 2013). TRPA1 has emerged as an important sensor of noxious stimuli and tissue damage. TRPA1 is activated by many natural compounds that cause pain and inflammation such as mustard oil, garlic, cinnamon and wasabi, environmental irritants present in air pollution, vehicle exhaust and cigarette smoke, or products of oxidation (Taylor-Clark et al. 2008, Taylor-Clark et al. 2009, Nassenstein et al. 2008, Bautista et al. 2013). The agonists of GPCRs such as prostaglandin $\mathrm{E}_{2}$ and bradykinin activate nociceptive neurons indirectly via interaction with TRPA1 (Nassenstein et al. 2008, Taylor-Clark et al. 2008, Grace et al. 2012). TRPA1 channels mediate the tussive response in both animals and human. Several studies in guinea pigs have provided direct and compelling evidence that TRPA1 agonists evoke coughing in a manner that can be antagonized by TRPA1 antagonists (Andre et al. 2009, Birrell et al. 2009, Brozmanova et al. 2012). When we compared the efficacy of TRPA1 vs. TRPV1 in our laboratory, we found that TRPA1-induced cough was relatively moderate in naïve guinea pigs compared to the cough initiated by TRPV1, likely due to a lower efficacy of TRPA1 stimulation to induce sustained activation of airway C-fibers. It may be speculated, however, that the efficacy of TRPA1 stimulation to trigger cough is increased in inflammatory conditions (Brozmanova et al. 2012).

TRPM8 (melastatin 8) channel has been described as a cold and menthol-activated channel with voltage-dependent gating properties (McKemy et al. 2002). TRPM8 is predominantly expressed in coldresponsive primary afferent sensory neurons within the DRG, trigeminal and jugular ganglia and are largely distinct from neurons expressing TRPV1 and TRPA1 (Nassenstein et al. 2008, Grace et al. 2014, Plevkova et al. 2013). TRPM8 is activated by cooling sensation compounds such as menthol, icilin and eucalyptol (McKemy et al. 2002, Grace et al. 2014, Plevkova et al. 2013). Several papers support the fact that TRPM8 channel plays a protective role and suppresses citric acid and capsaicin induced cough in animal and man (Morice et al. 1994, Buday et al. 2012, Plevkova et al. 2013). However, there are still controversial data relating to the role of TRPM8 because both menthol and icilin activate TRPA1 at high concentration (Grace et al. 2014). 
Acid-sensing ion channels (ASICs) contribute to airway nociception and are partialy responsible for airway defensive mechanisms including cough. ASIC channels are members of the DEG/ENaC family of sodium channels that are the cation channels gated by a proton. Some subunits are expressed in the peripheral sensory neurons and they determinate its acid transduction properties. The $\mathrm{pH}$ threshold of ASICs is in a wide range ( $\mathrm{pH}: 7-4)$. The overall acid responsiveness of a nerve terminal is influenced by other channels modulated by acid. Acid activates both TRPV1 and ASIC channels in sensory neurons. However, TRPV1 is not expressed in A $\delta$ fibers and selective TRPV1 inhibitors have no effect on acid-induced A $\delta$ fibers activation (Kollarik and Undem, 2002).

$P 2 X 2$ and $P 2 X 3$ channels have been found on sensory C-fibers. ATP activates ionotropic $\mathrm{P} 2 \mathrm{X}$ receptors and metabotropic $\mathrm{P} 2 \mathrm{Y}$ receptors. $\mathrm{P} 2 \mathrm{X} 3$ is predominantly expressed in the afferent airways $\mathrm{C}$ and A $\delta$ fibers. ATP has been shown to activate nodose and jugular sensory fibers, which was blocked by the selective P2X3 antagonist (Kwong et al. 2008). In human, ATP induced cough and bronchoconstriction in patients with asthma and COPD (Basoglu et al. 2015).

\section{Sensory hyperresponsiveness and cough}

There are many pieces of evidence that an excessive and troublesome cough may be a consequence of airway inflammation or chronic stimulation of airways by irritants leading to cough hypersensitivity and hyperactivity (Karlsson 1993, Carr 2004, Undem et al. 2015, Zaccone et al. 2016). Both peripheral and central sensitization of airway sensory nerves has been recognised as potential mechanisms of abnormal acute or chronic cough resulting from airway inflammation. Cough hypersensitivity is most likely associated with dysregulation of sensory neural pathways and cough reflex central regulation (Karlsson 1993, Carr 2004, Undem et al. 2015, Zaccone et al. 2016).

There are several experimental and clinical aspects for evaluation of cough reflex sensitivity, intensity, frequency and severity. Inhalation airway challenge using tussive agents such as citric acid and capsaicin has been used for both experimental research and clinical trials using regulation according to ERS guideline on the assessment of cough (Morice et al. 2007, Birrell et al. 2009, Laude et al. 1993, Karlsson 1993, Lalloo et al. 1995, Pecova et al. 2007). Cough reflex sensitivity is measured in individual subjects before and after the intervention and is recorded as the concentration of tussive substances inducing two (C2) or five (C5) coughs (Morice et al. 2007).

Previous experimental studies in animals have already shown that airway inflammation or chronic irritation with cigarette smoke may lead to hyperactivity in capsaicin-sensitive afferent nerves. Prolonged exposure of guinea pigs to cigarette smoke caused increased sensitivity to tussive citric acid and reactivity of capsaicin-sensitive nerves mediating cough (Karlsson 1993). Respiratory tract viral infection also induced cough hypersensitivity in response to capsaicin, citric acid and bradykinin in the guinea pig model (Zaccone et al. 2016). Many inflammatory mediators, such as histamine, bradykinin and prostaglandins, have been shown to increase nociceptor excitability and lead to development of cough hypersensitivity, as well (Choudry et al. 1989, Lee and Morton 1993, Kwong and Lee 2005, Fox at al. 1996, Kamei and Takahashi 2006, TaylorClark 2015). Increased cough reflex sensitivity and reactivity was observed in animals with allergic rhinitis (Brozmanova et al. 2006, Brozmanova et al. 2008). Cough reflex was correspondingly modulated by stimulation of nasal mucosa in cats and guinea pigs (Plevkova et al. 2004a). An alternative explanation for cough associated with rhinosinusitis would be a sensitizing effect of upper airway afferent nerves, resulting in enhanced cough responsiveness.

The clinical observation supports the existence of cough sensory hyperresponsiveness to tussive agents. Likely as in experimental animals, cough sensitivity was increased in humans with allergic rhinitis (Pecova et al. 2008). Coughing in response to experimental airway challenge with a range of physical and chemical irritants, including cold air and aerosols of capsaicin, citric acid, histamine, and charcoal dust, have been reported in both healthy subjects and patients with the disease (Choudry et al. 1989, Doherty et al. 2000). There is evidence that chronic inflammation of the lower airways with damaged bronchial epithelium and goblet cells hyperplasia may be related to neuropathic modulation. Some of these findings have been associated with capsaicin cough hypersensitivity (Choudry et al. 1989, Doherty et al. 2000, Niimi and Chung 2015). Increased level of inflammatory biomarkers including histamine, prostaglandin $\mathrm{D}_{2}$ and $\mathrm{E}_{2}, \mathrm{TNF} \alpha$ and IL-8 were found in the sputum of patients with chronic cough (Niimi and Chung 2015). Both bradykinin and $\mathrm{PGE}_{2}$ increase 
capsaicin cough response and indirectly sensitize airway neuronal response to capsaicin via activation of TRPV1 (Niimi and Chung 2015). Cough hypersensitivity correlates with increased expression of TRPV1 receptor on epithelial nerves of chronic cough patients (Groneberg et al. 2004). Moreover, the inflammation processes can also change electrical excitability and gene expression. If these changes are long-lasting, they can alter the phenotype of the $\mathrm{C}$ - and $\mathrm{A} \delta$-fibers in the airways which is often referred to as neuroplasticity. Subsequently these nerves can be activated by stimuli that normally do not evoke cough. For instance, inflammation of airways leads to expression of TRPV1 channels in nodose $\mathrm{A} \delta$-fibers in the trachea and thus becoming sensitive to TRPV1 activators in guinea pig model (Mazzone and Undem 2016). Interestingly, cough may be sensitized not only from the nose or upper airways respectively but also from outside the respiratory system, such as from oesophagus (Kollarik and Brozmanova 2009, Hennel et al. 2015).

\section{Voltage-gated sodium channels as potential targets in the regulation of cough}

Coughing associated with acute and chronic inflammation is ascribed to the activation of vagal airway sensory C-fibers. Numerous inflammatory mediators can act on multiple receptors expressed in airway $\mathrm{C}$-fibers. They involve histamine, bradykinin, prostaglandins and others, those have been shown to increase nociceptor excitability and increase the sensitivity of the cough reflex as well (Choudry et al. 1989, Lee and Morton 1993, Kwong and Lee 2005, Fox at al. 1996, Kamei and Takahashi 2006, Taylor-Clark 2015). Regardless of which receptors are stimulated, afferent activation depends on the gating of membrane ion channels at the airway afferent terminals. This leads to nerve depolarization, which triggers the activation of voltagegated sodium channels $(\mathrm{NaVs})$, which in turn are responsible for the induction and conduction of action potential (Carr and Undem 2003).

The therapeutic perspectives are still developed with a strategy of looking for effective antitussives mainly targeting $\mathrm{C}$-fibers for peripherally acting antitussive drugs. Previously, several studies were conducted when TRPV1 was considered as a strong candidate target for the development of novel antitussive agents (Morice and Geppetti 2004). However, contrary to expectations, a TRPV1 antagonist failed to show any significant benefit in reducing cough (Song and Morice 2017). Similarly, another candidate therapeutic target TRPA1, acting on vagal sensory neurons, failed in the convincing reduction of cough in studies using TRPA1 antagonists (Song and Morice 2017). ATP receptors $P 2 X 2 / 3$ antagonists were particularly effective on cough intensity, however, side effects such a loss of taste occurred (Ford and Undem 2013). Many other currently used antitussive therapies are ineffective and act largely through the central nervous system, therefore have numbers of dangerous adverse effects (Dicpinigaitis et al. 2014). The most common over-the-counter (OTC) antitussive medications sold are drugs containing dextromethorphan hydrobromide. Dextromethorphan is as effective as codeine and has neurological adverse effects in overdose. There are many other OTC antitussive drugs without available evidence for their effectiveness, but with higher numbers of adverse effects (Dicpinigaitis et al. 2014). Nevertheless, advances in the understanding of the mechanism of cough hypersensitivity offer the promise for new therapies targeting voltage-gated sodium channels predominantly peripherally acting antitussive drugs with minimal adverse effects. Among the nine subtypes of NaV1s channels, NaV1.7, NaV1.8 and NaV1.9 channels are almost exclusively expressed by sensory neuron $\mathrm{C}$-fibers and $\mathrm{A} \delta$-fibers that innervate the airways and initiate cough (Kwong et al. 2008a, Carr 2013, Muroi et al. 2013, Keller et al. 2017, Sun et al. 2017, Kollarik et al. 2018).

Electrophysiological analysis suggests substantial differences in NaVs regulation of different types of cough-triggering nerve afferents. The action potential initiation in nerve terminals of nodose $\mathrm{A} \delta$-fibers strongly depends on tetrodotoxin TTX-sensitive NaV1.7 channels, whereas the action potential initiation in nerve terminals of jugular C-fibers is dependent on TTX-resistant NaV1.8 channels (Sun et al. 2017, Kollarik et al. 2018). These channels come to be upregulated in response to inflammatory mediators that are known to increase cough sensitivity (Laedermann et al. 2015).

It appears that blockers of $\mathrm{NaV1.7}, \mathrm{NaV} 1.8$ and NaV1.9 channels have a potential for suppressing sensory nerve activity. In addition, $\mathrm{NaVs}$ channels are important in sensory nerve excitability and their inhibition may anaesthetize the airways (Keller et al. 2017). For instance, non-selective blocking of $\mathrm{NaVs}$ channels with local anaesthetics, such as lidocaine reduces but does not abolish cough evoked by mechanical and chemical stimuli (Muroi et al. 2013). A similar effect has been observed when using the knockdown of NaV1.7genesilencing approaches (Muroi et al. 2013). Clinical studies 
have shown that lidocaine is minimally effective at blocking cough, likely due to its low affinities for $\mathrm{NaVs}$ channels and it is likely that at the doses that can be administered safely, they only weakly and briefly inhibit $\mathrm{NaVs}$ in the afferent C-fibers and A $\delta$-fibers terminals involved in cough (Muroi and Undem 2014, Lavorini et al. 2016). The lidocaine derivative carcainium chloride has shown some antitussive potential without major local anaesthetic activity (Lavorini et al. 2016). Contrary, the novel voltage-gated sodium channel inhibitor GSK2339345 surprisingly increased cough (Smith et al. 2017). Among many controversial data in clinical trials using nebulized lidocaine about $50 \%$ of patients reported successful cough suppression and more than $40 \%$ of patients reported some side effects including dysphonia, oropharyngeal numbness, and bitter taste, so larger randomized control trials comparing nebulized lidocaine to placebo need to be conducted in the future (Sunders and Kirkpatrick 1984, Trochtenberg 1994, Lim et al. 2013, Truesdale and Jurdi 2013).

We recently reported the effect of lidocaine on citric acid- and capsaicin-induced cough in a guinea pig model. Our data have shown that nebulized lidocaine in a lower concentration of $1 \mathrm{mM}$ was not sufficient to reduce the tussive response evoked by citric acid, but inhalation of nebulized lidocaine in higher concentration (10 $\mathrm{mM})$ was successful in suppressing cough response during citric acid and capsaicin challenge (Svajdova et al. 2019). It has been previously established that nebulized lidocaine inhibited chemically induced cough evoked by capsaicin and citric acid in a dose-dependent manner and was ineffective against bronchoconstriction in conscious guinea pig model (Forsberg et al. 1992). In anaesthetized rabbits, both chemically (ammonia vapour) and mechanically evoked cough were inhibited by nebulized lidocaine and tetracaine (Karlsson 1987). Adcock and colleagues compared antitussive effects of two distinct local anaesthetics including lidocaine and carcainium chloride (RSD931). In awake guinea pigs, lidocaine aerosol in the concentration of 10 and $30 \mathrm{mg} / \mathrm{ml} \mathrm{did} \mathrm{not}$ significantly reduce the total number of coughs induced by citric acid and capsaicin. On the contrary, RSD931 significantly suppressed citric acid- and capsaicin-evoked cough (Adcock et al. 2003). In addition to that, no significant reduction in cough response was observed in guinea pigs pre-treated with nebulized lidocaine hydrochloride in concentrations of $100 \mathrm{mg} / \mathrm{ml}$ during capsaicin challenge, but RSD931 was again significantly effective in suppressing capsaicin-induced cough
(Venkatasamy et al. 2010).

The single-cell RT-PCR data shows that extrapulmonary jugular C-fibers and nodose $\mathrm{A} \delta$-fibers in guinea pig trachea express mainly TTX-sensitive NaV1.7 channels and TTX-resistant NaV1.8 and NaV1.9 channels (Kollarik et al. 2018, Sun et al. 2017). The significant progress in the understanding of voltage-gated sodium channels $(\mathrm{NaVs})$ proposed a hypothesis that blocking of certain NaV1 subtypes (namely NaV1.7 and NaV1.8) in airway sensory nerves may lead to suppression of pathological coughing (Muroi and Undem 2014).

\section{NaV1.8 blocker and cough}

$\mathrm{NaV} 1.8$ as one subtype of $\mathrm{NaVs}$ channels has a fundamental role on the neuron excitability and capacity for action potential discharge in vagal sensory neurons (Muroi and Undem 2014). NaV1.8 together with NaV1.7 and NaV1.9 appear to be upregulated in the presence of inflammation and specific inflammatory mediators (Strickland et al. 2008).

We recently demonstrated that the NaV1.8 inhibitor A-803467 suppressed capsaicin-induced cough in the dose that did not affect the respiratory rate (Brozmanova et al. 2019). The inhibitor was administered both in systemic and localized manner - by inhalation. Compared to vehicle, intraperitoneal or inhalation administration of A-803467 did not abolish cough completely but caused 30-50\% inhibition of capsaicininduced cough in naïve guinea pigs. This is consistent with electrophysiological studies, which demonstrated that bradykinin-induced action potential discharge in guinea pig jugular C-fibers was inhibited by NaV1.8 blocker by $50 \%$ (Kollarik et al. 2018). Likewise, NaV1.8 inhibitor A-803467 in a relatively large concentration did not entirely inhibit the TTX-resistant current in guinea pig neurons in the patch-clamp study (Brozmanova et al. 2019).

There is evidence that airway inflammatory processes lead to overexpression of $\mathrm{NaVs}$ channels such as NaV1.8 together with NaV1.7 and NaV1.9 in afferent nerves mediating cough (Strickland et al. 2008). Changes in the expression of $\mathrm{NaVs}$ contribute to the sensitization of sensory neurons in chronic pain states as well (Bennett et al. 2019). It seems that NaV1.8 blockade with NaV1.7 may normalize $\mathrm{C}$-fibers that are in a hyperexcitable state as a reaction to inflammation. In somatosensory system, blocking NaV1.8 has a limited effect on the response to 
painful stimuli in healthy animals, but considerably inhibits the hyperalgesia associated with inflammatory lesions (Lai et al. 2004, Jarvis et al. 2007). This may most likely explain the fact that Nav1.8 blockade is more effective in hypertussive state accompanied by respiratory diseases than in inhibiting cough in healthy individuals. Moreover, the systemic NaV1.8 blocker A803467 can affect different parts of C-fibers such as terminals, axons or cell bodies, however, the effect of inhaled A-803467 is most probably limited to C-fiber terminals in the airways.

Joshi with co-workers demonstrated additive antinociceptive effects of the selective NaV1.8 blocker A-803467 and selective TRPV1 antagonists in rat inflammatory and neuropathic pain models. Using such a combination to produce analgesia may potentially provide an improved therapeutic strategy (Joshi et al. 2009).

\section{NaV1.7 blocker and cough}

$\mathrm{NaV} 1.7$ is a tetrodotoxin-sensitive voltage-gated sodium channel and plays a critical role in the generation and conduction of action potentials in excitable tissues. Together with NaV1.8 and NaV1.9, NaV1.7 is abundantly expressed in airway vagal sensory neurons mediated initiating of cough (Kwong et al. 2008). NaV1.7 strongly regulates vagal afferent nerve excitability and is essential for conduction of action potential in vagal afferent nerves (Kwong et al. 2008, Kollarik et al. 2018, Muroi et al. 2011, Muroi et al. 2013). Single-cell RT-PCR performed on vagal afferent neurons from guinea-pig trachea has shown that almost all of the jugular TRPV1-positive neurons expressed NaV1.7. Tracheal nodose TRPV1-negative neurons also expressed NaV1.7 (Kollarik et al. 2018). The expression of NaV1.7 was in accordance with electrophysiology study from isolated vagal nodose and jugular nerve fibers innervating trachea or lung revealing that action potential conduction in the majority of jugular C-fibers was abolished by TTX. Contrary, both action potential initiation and conduction in nodose nociceptors were abolished by TTX or selective NaV1.7 blocker (Kollarik et al. 2018). The specific role of $\mathrm{NaV} 1.7$ in vagal afferent neurons has been shown when NaV1.7 gene expression was silenced in guinea pig nodose and jugular neurons. NaV1.7 gene expression in vagal ganglia was effectively and selectively reduced without changes in expression of other voltage-gated sodium channels subtypes. Reduced gene expression of NaV1.7 corresponded with a reduction of TTX-sensitive voltage-gated sodium current reflecting in the reduction of action potential discharge (Muroi et al. 2011, Muroi et al. 2013).

When used silencing NaV1.7 gene expression in vivo on citric acid-induced cough in awake guinea pigs, the cough response was almost abolished in animals bilaterally treated with NaV1.7 shRNA although their behavior was normal. In contrast to cough reflex, silencing NaV1.7 expression bilaterally in nodose neurons had no effect on respiratory rate (Muroi et al. 2011). It appears that blocking of the NaV1.7 channels prevent action potential conduction in most jugular Cfibers but did not block the action potential initiation (Kollarik et al. 2018). Inhibition of action potential activation of jugular C-fibers terminals appeared after the combination of inhaled NaV1.7 and NaV1.8 blockers (Kollarik et al. 2018, Patil et al. 2019). As seen, the role and function of $\mathrm{NaVs}$ channels at the terminals in the airways are more complex. Therefore, other experiments with NaV1.7 blockers focused on cough reflex are required using animal cough challenge model focused on topical - inhaled drug administration.

\section{Conclusion}

It is no doubt that increased activation of airway vagal nociceptors in pathological conditions is accompanied by the pathological type of coughing resulting from dysregulation of the neural pathway that controls cough. A large spectrum of mediators associated with airway inflammation overstimulates these vagal airway fibers including C-fibers leading to hypersensitivity and hyperreactivity. Therefore, inhibiting the activity of these vagal $\mathrm{C}$-fibers represents a rational approach to the development of effective antitussive drugs. This may be achieved by blocking inflammatory mediator receptors or by blocking the generator potential associated with the specific ion channels. Despite the strong efforts of pharmacological companies, many antitussive drugs are not effective and mainly centrally acting antitussive drugs have unwanted side effects. Because voltage-gated sodium channels are absolutely required for action potentials initiation and conduction irrespective of the stimulus, $\mathrm{NaVs}$ become a promising and attractive neural target. There is evidence that NaV1.7, 1.8 and 1.9 subtypes are predominantly expressed in airway cough-triggering nerves. The advantage of blocking these $\mathrm{NaVs}$ is silencing $\mathrm{C}$-fiber in 
action irrespective the stimulus, but the disadvantage is that by silencing the nerves it may also block beneficial sensations and neuronal reflex behavior. Therefore, the new strategy of pharmaceutical companies involves blocking the generator potential of nerves and an effort to find novel non-opioid analgesics. One suggests that new antitussive drugs would have the advantage of targeting airway nociceptors topically with an inhaled drug delivery approach without inhibiting the protective cough reflex.

Larger studies are needed for new therapies such as symptom-suppressive antitussives for chronic hypersensitivity syndrome. There are many parallels between chronic neuropathic pain and chronic cough and so this makes voltage-gated sodium channels blockers an attractive therapeutic approach.

\section{Conflict of Interest}

There is no conflict of interest.

\section{Acknowledgements}

This work was supported by Vega grant 1/0020/19 and Biomed Martin (ITMS: 26220220187).

\section{References}

ADCOCK JJ, DOUGLAS GJ, GARABETTE M, GASCOIGNE M, BEATCH G, WALKER M, PAGE CP: RSD931, a novel anti-tussive agent acting on airway sensory nerves. Br J Pharmacol 138: 407-416, 2003. https://doi.org/10.1038/sj.bjp.0705056

ANDRE E, GATTI R, TREVISANI M, PRETI D, BARALDI PG, PATACCHINI R, GEPPETTI P: Transient receptor potential ankyrin receptor 1 is a novel target for protussive agents. Br J Pharmacol 158: 1621-1628, 2009. https://doi.org/10.1111/j.1476-5381.2009.00438.x

BARNES PJ: The problem of cough and development of novel antitussives. Pulm Pharmacol Ther 20: 416-422, 2007. https://doi.org/10.1016/j.pupt.2006.11.001

BASOGLU OK, BARNES PJ, KHARITONOV SA, PELLEG A: Effect of aerosolized adenosine 5'-triphosphate in smokers and patients with COPD. Chest 148: 430-435, 2015. https://doi.org/10.1378/chest.14-2285

BAUTISTA DM, PELLEGRINO M, TSUNOZAKI M: TRPA1: a gatekeeper for inflammation. Annu Rev Physiol 75: 181-200, 2013. https://doi.org/10.1146/annurev-physiol-030212-183811

BELVISI MG, GEPPETTI P: Cough. 7: Current and future drugs for the treatment of chronic cough. Thorax 59: 438440, 2004. https://doi.org/10.1136/thx.2003.013490

BENNETT DL, CLARK AJ, HUANG J, WAXMAN SG, DIB-HAJJ SD: The role of voltage-gated sodium channels in pain signalling. Physiol Rev 99: 1079-1151, 2019. https://doi.org/10.1152/physrev.00052.2017

BIRRELL MA, BELVISI MG, GRACE M, SADOFSKY L, FARUQI S, HELE DJ: TRPA1 agonists evoke coughing in guinea pig and human volunteers. Am J Respir Crit Care Med 180: 1042-1047, 2009. https://doi.org/10.1164/rccm.200905-06650C

BONVINI SJ, BELVISI MG: Cough and airway disease: The role of ion channels. Pulm Pharmacol Ther 47: 21-28, 2017. https://doi.org/10.1016/j.pupt.2017.06.009

BROZMANOVA M, CALKOVSKY V, PLEVKOVA J, BARTOS V, PLANK L, TATAR M: Early and late allergic phase related cough response in sensitized guinea pigs with experimental allergic rhinitis. Physiol Res 55: $577-$ 584, 2006.

BROZMANOVA M, PLEVKOVA J, TATAR M, KOLLARIK M: Cough reflex sensitivity is increased in the guinea pig model of allergic rhinitis. J Physiol Pharmacol 59 (Suppl 6): 153-161, 2008.

BROZMANOVA M, MAZUROVA L, RU F, TATAR M, KOLLARIK M: Comparison of TRPA1-versus TRPV1mediated cough in guinea pigs. Eur J Pharmacol 689: 211-218, 2012. https://doi.org/10.1016/j.ejphar.2012.05.048

BROZMANOVA M, SVAJDOVA S, PAVELKOVA N, MUROI Y, UNDEM BJ, KOLLARIK M: The voltage-gated sodium channel NaV1.8. blocker A-803467 inhibits cough in the guinea pig. Respir Physiol Neurobiol 270: 103267, 2019. https://doi.org/10.1016/j.resp.2019.103267 
BUDAY T, BROZMANOVA M, BIRINGEROVA Z, GAVLIAKOVA S, POLIACEK I, CALKOVSKY V, SHETTHALLI MV, PLEVKOVA J: Modulation of cough response by sensory inputs from the nose - role of trigeminal TRPA1 versus TRPM8 channels. Cough 8: 11, 2012. https://doi.org/10.1186/1745-9974-8-11

CANNING BJ, MORI N, MAZZONE SB: Vagal afferent nerves regulating the cough reflex. Respir Physiol Neurobiol 152: 223-242, 2006. https://doi.org/10.1016/j.resp.2006.03.001

CANNING BJ, CHANG AB, BOLSER DC, SMITH JA, MAZZONE SB, MCGARVEY L: CHEST Expert Cough Panel. Anatomy and neurophysiology of cough: CHEST Guideline and Expert Panel Report. Chest 146: 16331648, 2014. https://doi.org/10.1378/chest.14-1481

CARR MJ: Plasticity of vagal afferent fibres mediating cough. Pulm Pharmacol Ther 17: 447-451, 2004. https://doi.org/10.1016/j.pupt.2004.09.020

CARR MJ: Regulation of cough and action potentials by voltage-gated Na channels. Pulm Pharmacol Ther 26: 508509, 2013. https://doi.org/10.1016/j.pupt.2013.07.001

CARR MJ, UNDEM BJ: Bronchopulmonary afferent nerves. Respirology 8: 291-301, 2003. https://doi.org/10.1046/j.1440-1843.2003.00473.x

CATERINA MJ, SCHUMACHER MA, TOMINAGA M, ROSEN TA, LEVINE JD, JULIUS D: The capsaicin receptor: a heat-activated ion channel in the pain pathway. Nature 389: 816-824. 1997. https://doi.org/10.1038/39807

CHEN Z, CHEN H, CHEN F, GU D, SUN L, ZHANG W, FAN L, LIN Y, DONG R, LAI K: Vagotomy decreases the neuronal activities of medulla oblongata and alleviates neurogenic inflammation of airways induced by repeated intra-esophageal instillation of $\mathrm{HCl}$ in guinea pigs. Physiol Res 66: 1021-1028, 2017. https://doi.org/10.33549/physiolres.933574

CHOUDRY NB, FULLER RW, PRIDE NB: Sensitivity of the human cough reflex: effect of inflammatory mediators prostaglandin $\mathrm{E}_{2}$, bradykinin and histamine. Am Rev Respir Dis 140: 137-141, 1989. https://doi.org/10.1164/ajrccm/140.1.137

DICPINIGAITIS PV, MORICE AH, BIRRING SS, MCGARVEY L, SMITH JA, CANNING BJ, PAGE CP: Antitussive drugs - past, present, and future. Pharmacol Rev 66: 468-512, 2014. https://doi.org/10.1124/pr.111.005116

DOHERTY MJ, MISTER MG, CALVERLEY PM: Capsaicin responsiveness and cough in asthma and chronic obstructive pulmonary disease. Thorax 55: 643-649, 2000. https://doi.org/10.1136/thorax.55.8.643

FORD AP, UNDEM BJ: The therapeutic promise of ATP antagonism at P2X3 receptors in respiratory and urological disorders. Front Cell Neurosci 7: 267, 2013. https://doi.org/10.3389/fncel.2013.00267

FORSBERG K, KARLSSON JA, ZACKRISSON C, PERSSON CG: Selective inhibition of cough and bronchoconstriction in conscious guinea pigs. Respiration 59: 72-76, 1992. https://doi.org/10.1159/000196030

FOX AJ, LALLOO UG, BELVISI MG, BERNAREGGI M, CHUNG KF, BARNES PJ: Bradykinin-evoked sensitization of airway sensory nerves: A mechanism for ACE-inhibitor cough. Nat Med 2: 814-817, 1996. https://doi.org/10.1038/nm0796-814

GRACE MS, BIRREL MA, DUBUIS E, MAHER SA, BELVISI MG: Transient receptor potential channels mediate the tussive response to prostaglandin $E_{2}$ and bradykinin. Thorax 67: 891-900, 2012. https://doi.org/10.1136/thoraxjnl-2011-201443

GRACE MS, BAXTER M, DUBUIS E, BIRREL MA, BELVISI MG: Transient receptor potential (TRP) channels in the airway: role in airway disease. Br J Pharmacol 171: 2593-2607, 2014. https://doi.org/10.1111/bph.12538

GRONEBERG DA, NIIMI A, DINH QT, COSIO B, HEW M, FISCHER, CHUNG KF: Increased expression of transient receptor potential vanilloid-1 in airway nerves of chronic cough. Am J Respir Crit Care Med 170: 1276-1280, 2004. https://doi.org/10.1164/rccm.200402-1740C

HENNEL M, BROZMANOVA M, KOLLARIK M: Cough reflex sensitization from esophagus and nose. Pulm Pharmacol Ther 35: 117-121, 2015. https://doi.org/10.1016/j.pupt.2015.10.007

HOWARD P, CAYTON RM, BRENNAN SR, ANDERSON PB: Lignocaine aerosol and persistent cough. Br Dis Chest 71: 19-24, 1977. https://doi.org/10.1016/0007-0971(77)90073-0

JARVIS MF, HONORE P, SHIEH CH, CHAPMAN M, JOSHI S, ZHANG XF, KORT M, CARROLL W, MARRON B, ATKONSON R, THOMAS J, LIU D, KRAMBIS M, LIU Y, MCGARAUGHTY S, CHU K, ROELOFFS 
R, ZHONG CH, MIKUSA JP, HERNANDEZ G, GAUVIN D, WADE C, ZHU CH, PAI M, SCANIO M, SHI L, DRIZIN I, GREGG R, MATULENKO M, HAKEEM A, GROSS M, JOHNSON M, MARSH K, WAGONER PK, SULLIVAN JP, FALTYNEK CR, KRAFTE DS: A-803467, a potent and selective NaV1.8 sodium channel blocker, attenuates neuropathic and inflammatory pain in rat. Proc Natl Acad Sci USA 104: 8520-8525, 2007. https://doi.org/10.1073/pnas.0611364104

JI Z, WANG Z, CHEN Z, JIN H, CHEN C, CHAI S, LV H, YANG L, HU Y, DONG R, LAI K: Melatonin attenuates chronic cough mediated by oxidative stress via transient receptor potential melastatin-2 in guinea pigs exposed to particulate matter 2.5. Physiol Res 67: 293-305, 2018. https://doi.org/10.33549/physiolres.933654

JOSHI SK, HONORE P, HERNANDEZ G, SCHMIDT R, GOMTSYAN A, SCANIO M, KORT M, JARVIS MF: Additive antinociceptive effects of the selective NaV1.8 blocker A-803467 and selective TRPV1 antagonists in rat inflammatory and neuropathic pain models. J Pain 10: 306-315, 2009. https://doi.org/10.1016/j.jpain.2008.09.007

KAMEI J, TAKAHASHI Y: Involvement of ionotropic purinergic receptors in the histamine-induced enhancement of the cough reflex sensitivity in guinea pigs. Eur J Pharmacol 547: 160-164, 2006. https://doi.org/10.1016/j.ejphar.2006.07.034

KARLSSON JA: Airway anaesthesia and the cough reflex. Bull Eur Physiopathol Respir 23 (Suppl 10): 29-36, 1987.

KARLSSON JA: A role for capsaicin sensitive, tachykinin containing nerves in chronic coughing and sneezing but not in asthma: a hypothesis. Thorax 48: 396-400, 1993. https://doi.org/10.1136/thx.48.4.396

KELLER JA, MCGOVERN AE, MAZZONE SB: Translating cough mechanisms into better cough suppressants. Chest 152: 833-841, 2017. https://doi.org/10.1016/j.chest.2017.05.016

KOLLARIK M, UNDEM BJ: Mechanisms of acid-induced activation of airway afferent nerve fibres in guinea pigs. J Physiol 543: 591-600, 2002. https://doi.org/10.1113/jphysiol.2002.022848

KOLLARIK M, UNDEM B: Activation of bronchopulmonary vagal afferent nerves with bradykinin, acid and vanilloid receptor agonists in wild-type and TRPV1-/-mice. J Physiol 555: 115-123, 2004. https://doi.org/10.1113/jphysiol.2003.054890

KOLLARIK M, BROZMANOVA M: Cough and gastroesophageal reflux: Insight from animal models. Pulm Pharmacol Ther 22: 130-134, 2009. https://doi.org/10.1016/j.pupt.2008.12.017

KOLLARIK M, RU F, BROZMANOVA M: Vagal afferent nerves with the properties of nociceptors. Auton Neurosci 153: 12-20, 2010. https://doi.org/10.1016/j.autneu.2009.08.001

KOLLARIK M, SUN H, HERBSTSOMER RA, RU F, KOCMALOVA M, MEEKER SN, UNDEM BJ: Different role of TTX-sensitive voltage-gated sodium channel $\left(\mathrm{Na}_{\mathrm{V}} 1\right)$ subtypes in action potential initiation and conduction in vagal airway nociceptors. J Physiol 596: 1419-1432, 2018. https://doi.org/10.1113/JP275698

KWONG K, LEE LY: Prostaglandin $\mathrm{E}_{2}$ potentiates a TTX-resistant sodium current in rat capsaicin-sensitive vagal pulmonary sensory neurons. J Physiol 564: 437-450, 2005. https://doi.org/10.1113/jphysiol.2004.078725

KWONG K, KOLLARIK M, NASSENSTEIN C, RU F, UNDEM BJ: P2X2 receptors differentiate placodal vs. neural crest C-fiber phenotypes innervating Guinea pig lungs and esophagus. Am J Physiol Lung Cell Mol Physiol 295: L858-L865, 2008. https://doi.org/10.1152/ajplung.90360.2008

KWONG K, CARR MJ, GIBBARD A, SAVAGE TJ, SINGH K, JING J, MEEKER S, UNDEM BJ: Voltage-gated sodium channels in nociceptive versus non-nociceptive nodose vagal sensory neurons innervating guinea pig lungs. J Physiol 586:1321-1336, 2008a. https://doi.org/10.1113/jphysiol.2007.146365

LAEDERMANN CJ, ABRIEL H, DECOSTERD I: Post-translational modifications of voltage-gated sodium channels in chronic pain syndromes. Front Pharmacol 6: 263, 2015. https://doi.org/10.3389/fphar.2015.00263

LAI J, PORRECA F, HUNTER JC, GOLD MS: Voltage-gated channels and hyperalgesia. Annu Rev Pharmacol Toxicol 44: 371-397, 2004. https://doi.org/10.1146/annurev.pharmtox.44.101802.121627

LALLOO UG, FOX AJ, BELVISI MG, CHUNG KF, BARNES PJ: Capsazepine inhibits cough induced by capsaicin and citric acid but not by hypertonic saline in guinea pigs. J Appl Physiol 79: 1082-1087, 1995. https://doi.org/10.1152/jappl.1995.79.4.1082

LAUDE EA, HIGGINS KS, MORICE AH: A comparative study of the effects of citric acid, capsaicin and resiniferatoxin on the cough challenge in guinea-pig and man. Pulm Pharmacol 6: 171-175, 1993. https://doi.org/10.1006/pulp.1993.1023 
LAVORINI F, SPINA D, WALKER MJ, FRANCIOSI L, PAGE CP, FONTANA GA: Antitussive effect of carcainium chloride in patients with chronic cough and idiopathic interstitial pseudomonias: a pilot study. Pulm Pharmacol Ther 40: 91-94, 2016. https://doi.org/10.1016/j.pupt.2016.08.001

LEE LY, MORTON RF: Histamine enhances vagal pulmonary C fiber responses to capsaicin and lung inflation. Respir Physiol 93: 83-96, 1993. https://doi.org/10.1016/0034-5687(93)90070-Q

LEVINE JD, ALESSANDRI-HABER N: TRP channels: Targets for the relief of pain. Biochim Biophys Acta 1772: 989-1003, 2007. https://doi.org/10.1016/j.bbadis.2007.01.008

LIM KG, RANK MA, HAHN PY, KEOGH KA, MORGENTHALER TI, OLSON EJ: Long-term safety of nebulized lidocaine for adults with difficult-to-control chronic cough: a case series. Chest 143: 1060-1065, 2013. https://doi.org/10.1378/chest.12-1533

MAZZONE SB: An overview of the sensory receptors regulating cough. Cough 1: 2, 2005. https://doi.org/10.1186/1745-9974-1-2

MAZZONE SB, UNDEM BJ: Cough sensors. V. Pharmacological modulation of cough sensors. Handb Exp. Pharmacol 187: 99-127, 2009. https://doi.org/10.1007/978-3-540-79842-2_6

MAZZONE SB, UNDEM BJ: Vagal Afferent innervation of the airways in health and disease. Physiol Rev 96: 9751024, 2016. https://doi.org/10.1152/physrev.00039.2015

MCKEMY DD, NEUHAUSSER WM, JULIUS D: Identification of a cold receptor reveals a general role for TRP channels in thermosensation. Nature 416: 52-58, 2002. https://doi.org/10.1038/nature719

MORICE AH, MARSHALL AE, HIGGINS KS, GRATTAN TJ: Effect of inhaled menthol on citric acid induced cough in normal subjects. Thorax 49: 1024-1026, 1994. https://doi.org/10.1136/thx.49.10.1024

MORICE AH, GEPPETTI P: Cough. 5: the type 1 vanilloid receptor: a sensory receptor for cough. Thorax 59: 257-258, 2004. https://doi.org/10.1136/thx.2003.013482

MORICE AH, FONTANA GA, BELVISI MG, BIRRING SS, CHUNG KF, DICPINIGAITIS PV, KASTELIK JA, McGARVEY LP, SMITH A, TATAR M, WIDDICOMBE J: ERS guidelines on the assessment of cough. Eur Respir J 29: 1256-1276, 2007. https://doi.org/10.1183/09031936.00101006

MUROI Y, RU F, KOLLARIK M, CANNING BJ, HUGHES SA, WALSH S, SIGG M, CARR MJ, UNDEM BJ: Selective silencing of Nav1.7 decreases excitability and conduction in vagal sensory neurons. J Physiol 589: 5663-5676, 2011. https://doi.org/10.1113/jphysiol.2011.215384

MUROI Y, RU F, CHOU YL, CARR MJ, UNDEM BJ, CANNING BJ: Selective inhibition of vagal afferent nerve pathways regulating cough using Nav 1.7 shRNA silencing in guinea pig nodose ganglia. Am J Physiol Regul Integr Comp Physiol 304: R1017-R1023, 2013. https://doi.org/10.1152/ajpregu.00028.2013

MUROI Y, UNDEM BJ: Targeting voltage gated sodium channels Nav1.7, Nav1.8, and Nav1.9 for treatment of pathological cough. Lung 192: 15-20, 2014. https://doi.org/10.1007/s00408-013-9533-X

NASSENSTEIN C, KWONG K, TAYLOR-CLARK T, KOLLARIK M, MACGLASHAN D, BRAUN A, UNDEM BJ: Expression and function of the ion channel TRPA1 in vagal afferent nerves innervating mouse lung. J Physiol 586: 1595-1604, 2008. https://doi.org/10.1113/jphysiol.2007.148379

NIIMI A, CHUNG KF: Evidence for neuropathic processes in chronic cough. Pulm Pharmacol Ther 35: 100-104, 2015. https://doi.org/10.1016/j.pupt.2015.10.004

PATIL MJ, SUN H, MEEKER S, UNDEM BJ: Targeting C-fibres for peripheral acting antitussive drugs. Pulm Pharmacol Ther 56: 15-19, 2019. https://doi.org/10.1016/j.pupt.2019.03.002

PECOVA R, JAVORKOVA N, KUDLICKA J, TATAR M: Tussigenic agents in the measurement of cough reflex sensitivity. J Physiol Pharmacol 58 (Suppl 5): 531-538, 2007.

PECOVA R, ZUCHA J, PEC M, NEUSCHLOVA M, HANZEL P, TATAR M: Cough reflex sensitivity testing in seasonal allergic rhinitis patients and healthy volunteers. J Physiol Pharmacol 59 (Suppl 6): 557-564, 2008.

PLEVKOVA J, BROZMANOVA M, PECOVA R, TATAR M: Effects of intranasal capsaicin challenge on cough reflex in healthy human volunteers. J Physiol Pharmacol 55 (Suppl 3): 101-106, 2004.

PLEVKOVA J, KOLLARIK M, BROZMANOVA M, REVALLO M, VARECHOVA S, TATAR M: Modulation of experimentally-induced cough by stimulation of nasal mucosa in cats and guinea pigs. Respir Physiol Neurobiol 142: 225-235, 2004a. https://doi.org/10.1016/j.resp.2004.06.006 
PLEVKOVA J, KOLLARIK M, POLIACEK I, BROZMANOVA M, SURDENIKOVA L, TATAR M, MORI M, CANNING B: The role of trigeminal nasal TRPM8-expressing afferent neurons in the antitussive effects of menthol. J Appl Physiol 115: 268-274, 2013. https://doi.org/10.1152/japplphysiol.01144.2012

SANDERS RV, KIRKPATRICK MB: Prolonged suppression of cough after inhalation of lidocaine in a patient with sarcoidosis. JAMA 252: 2456-2457, 1984. https://doi.org/10.1001/jama.252.17.2456

SMITH J, OWEN E, EARIS J, WOODCOCK A: Effect of codeine on objective measurement of cough in chronic obstructive pulmonary disease. J Allergy Clin Immunol 117: 831-835, 2006. https://doi.org/10.1016/j.jaci.2005.09.055

SMITH JA, MCGARVEY LPA, BADRI H, SATIA I, WARREN F, SIEDERER S, LIEFAARD L, MURDOCH RD, POVEZ K, MARKS-KONCYALIK J: Effects of a novel sodium channel blocker, GSK2339345, in patients with refractory chronic cough. Int J Clin Pharmacol Ther 55: 712-719, 2017. https://doi.org/10.5414/CP202804

SONG WJ, MORICE AH: Cough hypersensitivity syndrome: a few more steps forward. Allergy Asthma Immunol Res 9: 394-402, 2017. https://doi.org/10.4168/aair.2017.9.5.394

STRICKLAND IT, MARTINDALE JC, WOODHAMS PL, REEVE AJ, CHESSELL IP, MCQEEN DS: Changes in the expression of $\mathrm{Na}_{\vee} 1.7, \mathrm{Na}_{\mathrm{v}} 1.8$ and $\mathrm{Na}_{\mathrm{v}} 1.9$ in a distinct population of dorsal root ganglia innervating the rat knee joint in a model of chronic inflammatory joint pain. Eur J Pain 12: 564-572, 2008. https://doi.org/10.1016/j.ejpain.2007.09.001

SUN H, KOLLARIK M, UNDEM BJ: Blocking voltage-gated sodium channels as a strategy to suppress pathological cough. Pulm Pharmacol Ther 47: 38-41, 2017. https://doi.org/10.1016/j.pupt.2017.05.010

SVAJDOVA S, BUDAY T, BROZMANOVA M: Lidocaine, a non-selective inhibitor of voltage-gated sodium channels, blocks chemically-induced cough in awake naive guinea pigs. Adv Exp Med Biol 1160: 1-9, 2019. https://doi.org/10.1007/5584_2018_326

TAYLOR-CLARK TE, UNDEM BJ, MACGLASHAN DW, GHATTA S, CARR MJ, MCALEXANDER MA: Prostaglandin-induced activation of nociceptive neurons via direct interaction with transient receptor potential A1 (TRPA1). Mol Pharmacol 73: 274-281, 2008. https://doi.org/10.1124/mol.107.040832

TAYLOR-CLARK TE, NASSENSTEIN C, MCALEXANDER MA, UNDEM BJ: TRPA1: A potential target for antitussive therapy. Pulm Pharmacol Ther 22: 71-74, 2009. https://doi.org/10.1016/j.pupt.2008.12.019

TAYLOR-CLARK TE: Peripheral neural circuitry in cough. Curr Opin Pharmacol 22: 9-17, 2015. https://doi.org/10.1016/j.coph.2015.02.001

TROCHTENBERG S: Nebulized lidocaine in the treatment of refractory cough. Chest 105: 1592-1593, 1994. https://doi.org/10.1378/chest.105.5.1592

TRUESDALE K, JURDI A: Nebulized lidocaine in the treatment of intractable cough. Am J Hosp Palliat Care 30: 587589, 2013. https://doi.org/10.1177/1049909112458577

UNDEM BJ, ZACCONE E, McGARWAY L, MAZZONE SB: Neural dysfunction following respiratory viral infection as a cause of chronic cough hypersensitivity. Pharmacol Ther 33: 52-56, 2015. https://doi.org/10.1016/j.pupt.2015.06.006

VENKATASAMY R, MCKENZIE A, PAGE CP, WALKER MJ, SPINA D: Use of within-group designs to test antitussive drugs in conscious guinea-pigs. J Pharmacol Toxicol Methods 61: 157-162, 2010. https://doi.org/10.1016/j.vascn.2010.02.015

WEST PW, CANNING BJ, MERLO-PICH E, WOODCOCK AA, SMITH JA: Morphologic characterization of nerves in whole-mount airway biopsies. Am J Respir Crit Care Med 192: 30-39, 2015. https://doi.org/10.1164/rccm.201412-22930C

ZACCONE EJ, LIEU TM, MUROI Y, POTENZIERI C, UNDEM BE, GAO P, HAN L, CANNING BJ, UNDEM BJ: Parainfluenza 3-induced cough hypersensitivity in the guinea pig airways. PloS One 11: e015552, 2016. https://doi.org/10.1371/journal.pone.0155526 